\title{
The Influence of Climate Factors on Hand-Foot-Mouth Disease: A Five-State Study in Malaysia
}

\author{
Nurmarni Athirah Abdul Wahid ${ }^{1}$, Jamaludin Suhaila ${ }^{1,2, *}$, Haliza Abd. Rahman ${ }^{1}$ \\ ${ }^{1}$ Department of Mathematical Sciences, Faculty of Science, Universiti Teknologi Malaysia, Johor Bahru, Malaysia \\ ${ }^{2}$ UTM Centre of Industrial and Applied Mathematics (UTM-CIAM), Ibnu Sina Institute for Scientific and Industrial Research, \\ Universiti Teknologi Malaysia, Johor Bahru, Malaysia
}

Received August 20, 2021; Revised September 12, 2021; Accepted October 27, 2021

\begin{abstract}
Cite This Paper in the following Citation Styles
(a): [1] Nurmarni Athirah Abdul Wahid, Jamaludin Suhaila, Haliza Abd. Rahman, "The Influence of Climate Factors on Hand-Foot-Mouth Disease: A Five-State Study in Malaysia," Universal Journal of Public Health, Vol. 9, No. 5, pp. 324 - 331, 2021. DOI: 10.13189/ujph.2021.090515.
\end{abstract}

(b): Nurmarni Athirah Abdul Wahid, Jamaludin Suhaila, Haliza Abd. Rahman (2021). The Influence of Climate Factors on Hand-Foot-Mouth Disease: A Five-State Study in Malaysia. Universal Journal of Public Health, 9(5), 324 - 331. DOI: 10.13189/ujph.2021.090515.

Copyright $\bigcirc 2021$ by authors, all rights reserved. Authors agree that this article remains permanently open access under the terms of the Creative Commons Attribution License 4.0 International License

\begin{abstract}
Hand, foot, and mouth disease (HFMD) has become an important public health problem worldwide due to its tendency to cause outbreaks and human death. The outbreak of HFMD with clinical and fatal complications has been noticed in the Asia Pacific region since the late 1990s. The increasing evidence of climate change effect on HFMD has motivated the need for further investigations. Numerous previous studies conducted in several countries have established a significant association between climate factors and HFMD. However, there are currently only a few studies in Malaysia addressing these issues. Therefore, this study aimed to examine the link between climate factors and the occurrences of HFMD in five states representing each region of Malaysia by using a generalized linear model approach. The weekly HFMD cases and four climate variables, including temperature, humidity, rainfall, and wind speed, were examined. The findings indicate that climate variables significantly influence HFMD in Malaysia; however, it varies between states as different states experience different climates. Additionally, the results revealed that humidity and temperature were the primary climate factors affecting the incidence of HFMD in Malaysia. This study could guide policymakers, health agencies, and local communities in determining the most effective prevention and control strategies.
\end{abstract}

Keywords HFMD, Climate Change, Generalized Linear Model, Infectious Disease, Negative Binomial

\section{Introduction}

Hand, foot, and mouth disease (HFMD) was first announced clinically in New Zealand in early 1957 by Seddon [1]. Thomas Henry Flewett introduced the term for this disease in the year 1960 [2]. Two main types of human enteroviruses cause HFMD, namely Coxsackie Virus A16 and Enterovirus 71 (EV71). According to the Ministry of Health Malaysia, the symptoms of this disease include fever followed by blisters on the hands, feet, mouth, and tongue [3]. These symptoms will appear between three and seven days after the infection [4]. HFMD incidence has been documented for more than a decade, and the Western Pacific region is the most severely affected by this disease, for instance, China [5], Japan [6], Singapore [7], Thailand [8] and Malaysia. HFMD has been a massive burden on public health since the late 1990s in this area [9]. Besides, the number of deaths among children caused by severe complications appears to be rising across the Western Pacific region [10]. Public health concerns have increased, especially since the severe outbreak in Malaysia during the year 1997. In Malaysia, the HFMD disease was initially detected in Sarawak in April 1997 and then emerged in Peninsular Malaysia in June 1997 [11]. Some researchers in Malaysia revealed that HFMD cases have a three-year cyclical 
pattern in Malaysia [12].

There has been an increase in the literature regarding the influence of climate factors on the incidence of HFMD in numerous countries. However, different countries reported inconsistent findings. For instance, a study in Hong Kong [13], Japan [14], and South Korea [15], revealed that temperature and humidity are the critical factors that affect HFMD cases. Meanwhile, a study in China [16] reported that HFMD disease was positively associated only with wind speed at one week lag time. Apart from that, a study in Singapore has shown that the occurrences of HFMD are significantly associated with rainfall [17]. Nonetheless, it is contrary to a study in Japan [14], in which they indicate that there is no significant association between rainfall and HFMD occurrences. Since previous studies in various countries have produced different results, it is also important to investigate these issues in Malaysian cases. Climate factors are also suspected to be one of the leading causes of HFMD cases in Malaysia.

In determining the impact of climatic factors on HFMD, several studies have employed a generalized modeling approach, for example, a generalized linear model (GLM). GLM allows linear modeling of a wider class of response types, such as count data [18]. However, there is a limited study in Malaysia that establishes the link between climate variables and HFMD occurrences using statistical modeling techniques. Indeed, there is no concrete and consistent evidence related to these issues. The previous study only focused on the method of time-series analysis. Sham [19] performed a cross-sectional time series analysis to estimate the association between EV-A71 epidemic periods and EV-A71 seroprevalence while controlling for age and climate variables, including temperature, rainfall, rain days, and ultraviolet radiance. They found that the seroprevalence rate in children could be used to forecast the occurrence of EV-A71 epidemics and was influenced by temperature and the number of rainy days. Furthermore, a study conducted by NikNadia [20] modelled and forecasted HFMD cases in Sarawak using an autoregressive moving average (ARMA) time series analysis. They demonstrated that the ARMA $(1,4)$ model provides a fair fit and efficiently predicts that HFMD cases will occur within the $90 \%$ interval for the first 16 weeks of 2013.

Prior research in Malaysia indicates that the idea of generalized modeling in examining the influence of climate factors on HFMD incidence is still relatively new. Therefore, this study adopted a statistical generalized linear model (GLM) approach to examine the influence of climate factors on HFMD cases in five distinct states in Malaysia. This study may help health authorities in establishing early warning systems regarding climate change and may raise awareness of HFMD.

\section{Materials and Methods}

\subsection{Surveillance Data}

The weekly HFMD cases in five selected states of Malaysia, which include Kedah, Johor, Kelantan, Selangor, and Sarawak, from 2010 to 2016, are obtained from the Portal of Public Sector Open Data Malaysia. The selected states represent each division region in Malaysia, namely, Northern, Southern, East Coast, Central region of Peninsular Malaysia, and East Malaysia, respectively.

\subsection{Meteorological Data}

The weekly climate variables from 2010 to 2016, including temperature $\left({ }^{\circ} \mathrm{C}\right)$, relative humidity $(\%)$, rainfall $(\mathrm{mm})$, and wind speed $(\mathrm{m} / \mathrm{s})$, are obtained from the Malaysian Meteorological Department. Figure 1 shows the map of the selected states of Malaysia in this study.

\subsection{Methodology}

The delayed impacts of climate factors and incubation periods are taken into account in this study, as changes in climate conditions will affect HFMD activity. According to a previous study conducted in Hong Kong, the incubation period for HFMD was approximately one to three weeks [13], and hence we used a two-week lag effect of climate factors in the present study. Before proceeding with the modeling process, the multicollinearity of the climate factors was determined using several diagnostics measures, including the variance inflation factor (VIF), corrected variance inflation factor (CVIF), and tolerance (TOL). The presence of multicollinearity is indicated by VIF values which are greater than 5 [21], CVIF values greater than 10 [22], and TOL values close to zero [23]. As a result, collinear climate variables will be excluded from the model in this study. A generalized linear model (GLM) approach was used in this study to examine the impact of climate factors on the occurrence of HFMD in Malaysia. The GLM approach has been regarded as an important method in regression analysis [24]. Provided that the Poisson distribution can be applied for modeling variables of count data and it is a common process in clinical and epidemiological research [25], a GLM with family Poisson will be adopted in the first phase.

The Poisson distribution with parameter $\mu$ is given by formula as follows: 


$$
\begin{gathered}
f\left(Y ; \mu_{i}\right)=\frac{e^{-\mu_{i}} \mu_{i}^{y_{i}}}{y_{i} !}, \\
y_{i}=0,1,2,3, \ldots, \infty, i=1,2,3, \ldots, t
\end{gathered}
$$

where $Y$ is a response variable for a given period $t$, and $\mu_{i}$ is both mean and variance of $Y$.

However, one of the fundamental assumptions in modeling the Poisson regression model is that the mean and variance are equal. If the variance is greater than the mean, then overdispersion may exist in the data sets. This issue may underestimate standard errors, resulting in erroneous findings. The test of overdispersion implemented by Cameron and Trivedi [26] is used in this study to detect the overdispersion issue in the data sets for each selected state. Breslow [27] affirms that the negative binomial distribution can be used to address this issue as it is a convenient and practical approach. The negative binomial distribution is a Poisson gamma mixture. The expected value and variance for the negative binomial are $E\left(Y_{i}\right)=\mu_{i}$ and $\operatorname{Var}\left(Y_{i}\right)=\mu_{i}+\mu_{i}^{2} v_{i}^{-1}$, respectively. Thus, to solve the overdispersion challenges in this study, a GLM with a negative binomial distribution will be used. Equation (2) shows the negative binomial's probability density function.

$$
\begin{aligned}
f\left(Y ; \mu_{i}, v_{i}\right) & =\frac{\Gamma\left(y_{i}+v_{i}\right)}{\Gamma\left(v_{i}\right) \Gamma\left(y_{i}+1\right)}\left(\frac{v_{i}}{v_{i}+\mu_{i}}\right)^{v_{i}}\left(\frac{\mu_{i}}{v_{i}+\mu_{i}}\right)^{y_{i}}, \\
y_{i} & =0,1,2,3, \ldots, \infty, i=1,2,3, \ldots, t
\end{aligned}
$$

A GLM full model describing the HFMD cases and climate factors in each state can be written as in (3).

$$
\begin{gathered}
\ln \left[\text { E }\left(\text { HFMD }_{i}\right)\right]=\beta_{0}+\beta_{1}\left(\text { Temperature }_{i}\right)_{t-2} \\
+\beta_{2}\left(\text { Humidity }_{i}\right)_{t-2}+\beta_{3}\left(\text { Rainfall }_{i}\right)_{t-2} \\
+\beta_{4}\left(\text { Wind speed }_{i}\right)_{t-2}+\beta_{5}\left(\text { Time }_{i}\right)+\varepsilon_{i}
\end{gathered}
$$

where $i$ denotes the week of HFMD cases, $i=1,2,3, \ldots, 365$, and $\beta_{0}$ represents the intercept. The value $t-2$ is the effect of all climate variables over two weeks lag time, and $\varepsilon$ represents the error term which is assumed to be independently and normally distributed, such that $\varepsilon_{i} \sim N\left(0, \sigma_{\varepsilon}^{2}\right)$. These models include a covariate of time to adjust the long-term trend and seasonal effect in weekly cases.

Apart from that, the modeling method considers the covariate selection analysis to find the optimal model for GLM. A stepwise forward selection method based on the Akaike Information Criterion (AIC) has been used to evaluate whether climate factors should be included or excluded from the model. The AIC presents a mean of model selection and is often regarded as the best method for determining the most appropriate estimated model for the data [28]. The lowest AIC value indicates the best optimum models. The AIC is represented by the following formula:

$$
\mathrm{AIC}=2 k-2 \ln (L)
$$

where $k$ is the number of estimated parameters in the model and $L$ is the maximum value of the likelihood function for the model. In this study, parameters estimated with a $p$-value less than 0.05 were considered statistically significant. All analyses were carried out using the statistical programming language $\mathrm{R}$.

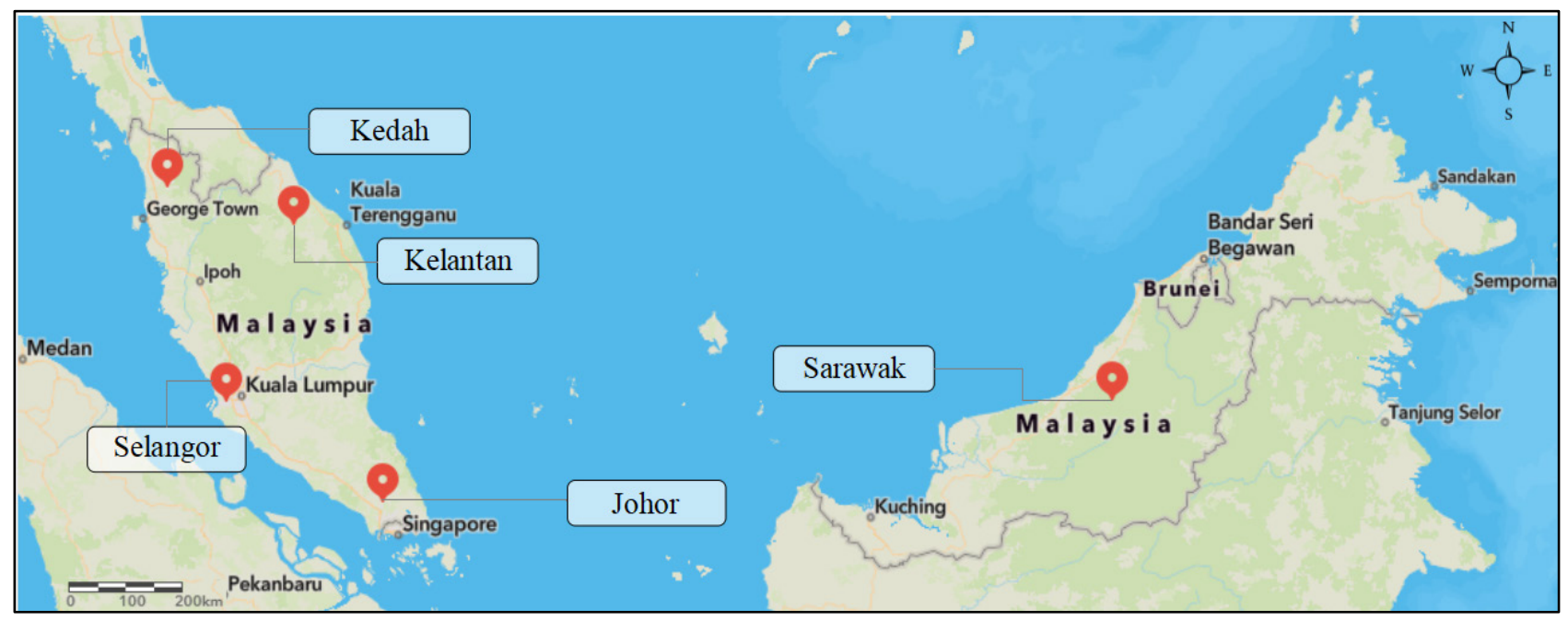

Figure 1. Map of five selected states in Malaysia 


\section{Results and Discussions}

\subsection{Summary of HFMD in Malaysia, 2010-2016}

The total number of HFMD cases from 2010 to 2016 for five selected states representing each region in Malaysia is illustrated in Figure 2. Sarawak records the highest total number of HFMD cases with 54832, while Selangor records the second-highest total number of cases, followed by Johor and Kedah with 43903, 13957, and
6164 cases, respectively. Moreover, the lowest total number of HFMD cases was recorded in Kelantan, with 3987 cases. Figure 3 illustrates the trend of HFMD cases in five selected states from 2010 to 2016 . The number of HFMD cases sharply increased from 2011 to 2012 in Sarawak and from 2015 to 2016 in Selangor. Additionally, it demonstrated that the trend of HFMD cases is comparable across all regions, with cases increasing in 2012, 2014, and 2016.

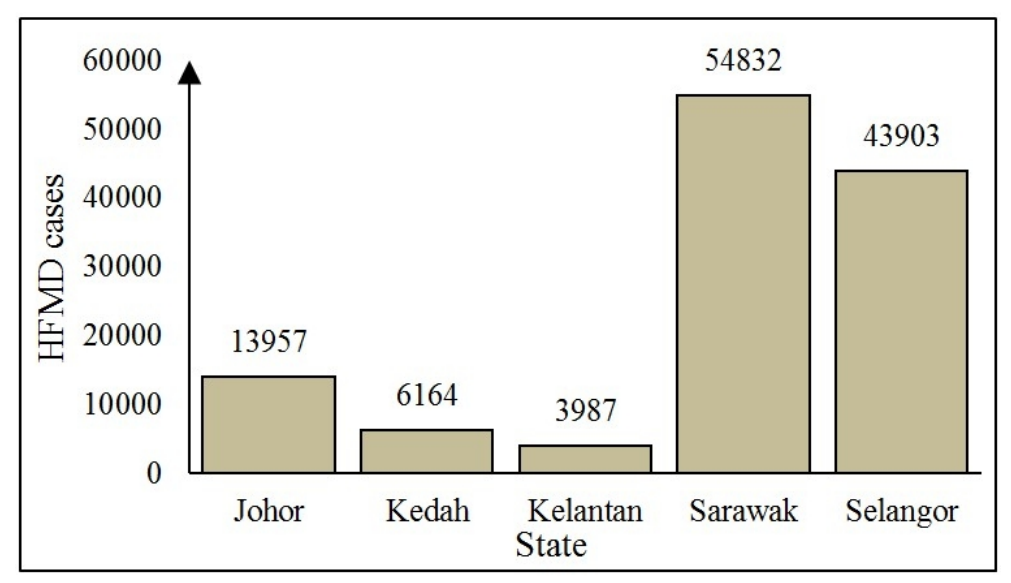

Figure 2. Total HFMD cases for five states in Malaysia, 2010-2016

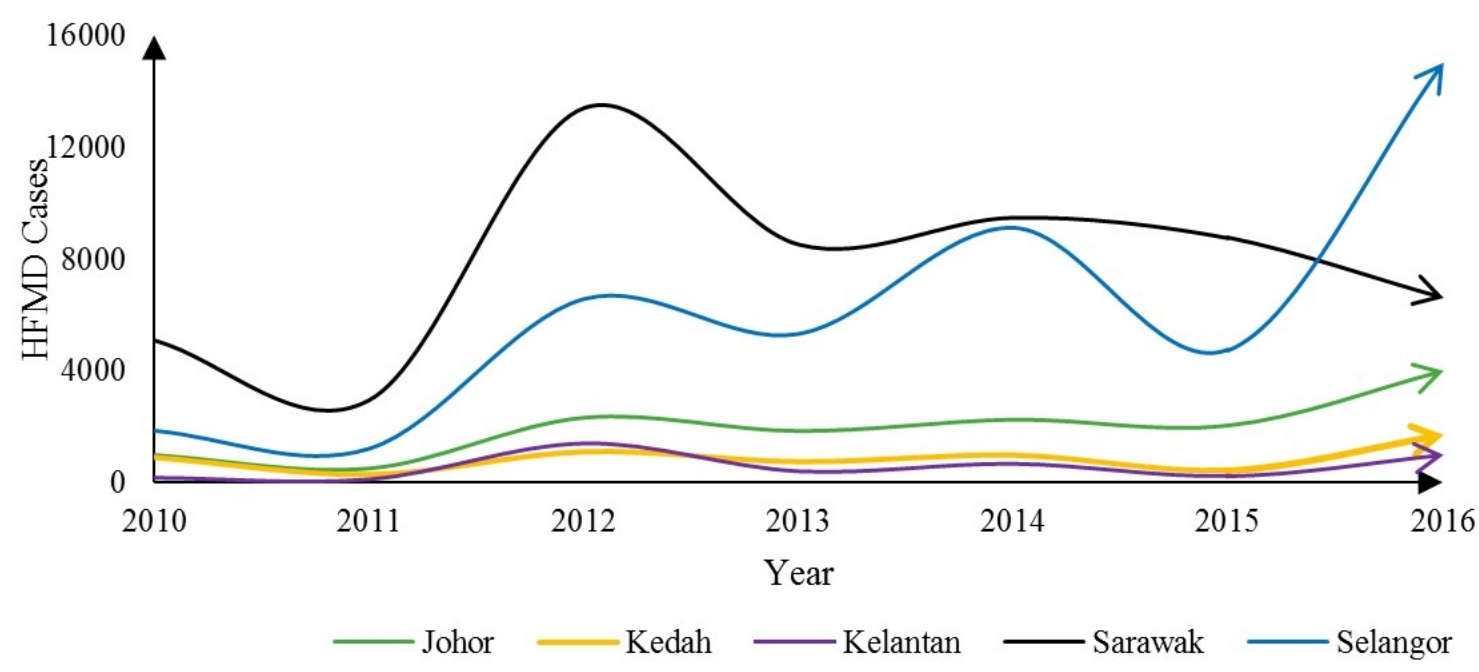

Figure 3. The trend of HFMD cases for five states in Malaysia, 2010-2016 
Table 1. Multicollinearity test for climate factors, specific state

\begin{tabular}{|c|c|c|c|c|c|}
\hline \multirow{2}{*}{ Region } & \multirow{2}{*}{ States } & \multirow{2}{*}{ Climate Factors } & \multicolumn{3}{|c|}{ Multicollinearity Test } \\
\cline { 3 - 6 } & & & VIF & Tolerance & CVIF \\
\hline \multirow{3}{*}{ Northern } & \multirow{3}{*}{ Kedah } & Temperature & 1.2957 & 0.7718 & 1.3140 \\
& & Humidity & 1.9795 & 0.5052 & 2.0074 \\
& & Rainfall & 1.3236 & 0.7555 & 1.3423 \\
& & Wind speed & 1.7832 & 0.5608 & 1.8083 \\
\hline \multirow{3}{*}{ Southern } & \multirow{3}{*}{ Johor } & Temperature & 2.3617 & 0.4234 & 2.4440 \\
& & Humidity & 3.5415 & 0.2824 & 3.6650 \\
& & Rainfall & 1.3560 & 0.7374 & 1.4033 \\
& & Wind speed & 2.0832 & 0.4800 & 2.1559 \\
\hline \multirow{3}{*}{ East Coast } & Kelantan & Temperature & 1.6334 & 0.6122 & 1.6312 \\
& & Humidity & 2.2907 & 0.4365 & 2.2876 \\
& & Rainfall & 1.7311 & 0.5777 & 1.7288 \\
& & Wind speed & 1.1815 & 0.8464 & 1.1799 \\
\hline \multirow{3}{*}{ Central } & \multirow{3}{*}{ Selangor } & Temperature & 1.9051 & 0.5249 & 1.8798 \\
& & Humidity & 2.1183 & 0.4721 & 2.0902 \\
& & Rainfall & 1.6466 & 0.6073 & 1.6247 \\
& & Wind speed & 1.3164 & 0.7596 & 1.2989 \\
\hline & & Temperature & 2.2973 & 0.4353 & 2.2772 \\
& & Humidity & 2.6593 & 0.3760 & 2.6360 \\
& & Rainfall & 1.5402 & 0.6493 & 1.5267 \\
& & Wind speed & 1.3082 & 0.7644 & 1.2967 \\
\hline
\end{tabular}

\subsection{Multicollinearity Test}

The results of a multicollinearity test performed on climate variables for each state in Malaysia, including temperature, humidity, rainfall, and wind speed, are shown in Table 1. The findings show that the VIF value is less than 5, the CVIF value is less than 10 , and the TOL value is greater than 0 . This implies that the datasets do not involve multicollinearity concerns. As a result, the model will include all climate factors.

\subsection{Overdispersion Test}

Table 2 summarizes the findings of the overdispersion test for data sets for each selected state. The findings show that the $p$-values are less than 0.05 and the data sets for each state have larger dispersion values. Thus, there is sufficient evidence to reject the null hypothesis, implying that the data sets for each state display issues with overdispersion. A GLM Negative Binomial model is, therefore, proposed to overcome these problems.

Table 2. Overdispersion test for datasets of each selected states

\begin{tabular}{|c|c|c|c|}
\hline \multirow{2}{*}{ States } & \multicolumn{3}{|c|}{ Overdispersion Test } \\
\cline { 2 - 4 } & Dispersion & $\boldsymbol{z}$-values & $\boldsymbol{p}$-values \\
\hline Kedah & 15.6967 & 6.7070 & $0.0000^{* * *}$ \\
\hline Johor & 35.7644 & 7.1308 & $0.0000^{* * *}$ \\
\hline Kelantan & 26.2840 & 4.1974 & $0.0000^{* * *}$ \\
\hline Selangor & 129.3425 & 8.3758 & $0.0000^{* * *}$ \\
\hline Sarawak & 122.6157 & 9.2299 & $0.0000^{* * *}$ \\
\hline
\end{tabular}

Significant codes: $0.05^{\prime * * *}$,

\subsection{Covariate Selection}

Table 3. Stepwise forward selection method of variables for Johor

\begin{tabular}{|c|c|c|}
\hline Step & Climate factors & AIC \\
\hline \multirow{4}{*}{1} & Temperature & 3288.7940 \\
\cline { 2 - 3 } & Humidity & 3311.5820 \\
\cline { 2 - 3 } & Rainfall & 3310.6650 \\
\cline { 2 - 3 } & Wind speed & 3302.7940 \\
\hline \multirow{3}{*}{2} & $\begin{array}{c}\text { Temperature } \\
\text { Humidity }\end{array}$ & 3285.6140 \\
\cline { 2 - 3 } & $\begin{array}{c}\text { Temperature } \\
\text { Rainfall }\end{array}$ & 3290.5670 \\
\cline { 2 - 3 } & $\begin{array}{c}\text { Temperature } \\
\text { Wind speed }\end{array}$ & $\mathbf{3 2 8 4 . 9 2 9 0}$ \\
\hline \multirow{3}{*}{3} & $\begin{array}{c}\text { Temperature } \\
\text { Wind speed } \\
\text { Humidity }\end{array}$ & 3286.5340 \\
\cline { 2 - 3 } & $\begin{array}{c}\text { Temperature } \\
\text { Wind speed } \\
\text { Rainfall }\end{array}$ & 3299.1720 \\
\hline 4 & All climate factors & 3288.2290 \\
\hline
\end{tabular}

***The bold represent the smallest values of AIC

The findings for the variable selection using a stepwise forward selection method for Johor are shown in Table 3. From the results, temperature indicates the best single predictor in the first step as it has the smallest value of AIC in comparison to the other predictors. The two predictor models were fitted in the second stage, with temperature as the first predictor and other climate factors as the second. The model that incorporates wind speed has the lowest AIC value, indicating that wind speed is the second important predictor. The analysis is continued 
using the three predictor models; nevertheless, adding predictors does not result in the smallest AIC value. Thus, temperature and wind speed are chosen as covariates to complete the optimal model for Johor. This process was repeated for the remaining selected states of Malaysia.

\subsection{Generalized Linear Model Approach}

Table 4 summarizes the results of the GLM negative binomial model for each selected state in Malaysia. The results demonstrate that a two-week delay in humidity has a significant effect on the occurrences of HFMD in all states except Johor in the Southern area, with a p-value less than 0.05. A positive linear relationship between HFMD cases and humidity was found in Kedah, Kelantan, and Selangor, but a negative linear relationship was observed in Sarawak in East Malaysia. Besides, there is a significant positive correlation between HFMD cases and temperature in Johor and Selangor at a two-week lag period, with a $p$-value less than 0.05. In Sarawak, however, there was a negative linear association. In addition, a negative association between two weeks of rainfall and the wind speed delay between HFMD occurrences was found in Kelantan and Johor with $p$-values below 0.05 , respectively.

Overall, this study indicates that humidity and temperature are the most common risk determinant for HFMD cases in Malaysia. These results are similar to several studies conducted in Japan [14], South Korea [15], Vietnam [29], and China [30-32]. Furthermore, the results indicate that the influence of climate factors on HFMD varied in Malaysia amongst states, possibly due to different geographical areas. These findings are aligned with a study in three distinct locations in China [33,34], where the climate variables are strongly correlated with geographic latitude and longitude, which could have an impact on the occurrence of HFMD cases.

Table 4. A GLM negative binomial model for HFMD cases in each selected state of Malaysia

\begin{tabular}{|c|c|c|c|c|c|c|c|c|}
\hline State & Model & Estimate & $\begin{array}{c}\text { Standard } \\
\text { Error }\end{array}$ & $p$-value & DOF & Deviance & $\begin{array}{c}\text { Mean } \\
\text { Deviance }\end{array}$ & AIC \\
\hline \multirow{3}{*}{ Kedah } & Constant & -2.9636 & 1.0765 & $0.0059 * * *$ & \multirow{3}{*}{362} & \multirow{3}{*}{406.25} & \multirow{3}{*}{1.1222} & \multirow{3}{*}{2780.289} \\
\hline & Humidity & 0.0240 & 0.0068 & $0.0004 * * *$ & & & & \\
\hline & Time & 0.2400 & 0.0614 & $0.0000 * * *$ & & & & \\
\hline \multirow{4}{*}{ Johor } & Constant & -10.7222 & 1.3276 & $0.0000 * * *$ & \multirow{4}{*}{361} & \multirow{4}{*}{395.98} & \multirow{4}{*}{1.0969} & \multirow{4}{*}{3284.929} \\
\hline & Temperature & 0.2289 & 0.0488 & $0.0000 * * *$ & & & & \\
\hline & Wind speed & -0.2171 & 0.0930 & $0.0196^{* * *}$ & & & & \\
\hline & Time & 0.5241 & 0.0604 & $0.0000 * * *$ & & & & \\
\hline \multirow{4}{*}{ Kelantan } & Constant & -9.1713 & 2.1753 & $0.0000 * * *$ & \multirow{4}{*}{361} & \multirow{4}{*}{417.78} & \multirow{4}{*}{1.1573} & \multirow{4}{*}{2476.010} \\
\hline & Humidity & 0.0629 & 0.0209 & $0.0026 * * *$ & & & & \\
\hline & Rainfall & -0.0166 & 0.0073 & $0.0237 * * *$ & & & & \\
\hline & Time & 0.41353 & 0.08613 & $0.0000 * * *$ & & & & \\
\hline \multirow{4}{*}{ Selangor } & Constant & -21.6881 & 3.1132 & $0.0000 * * *$ & \multirow{4}{*}{361} & \multirow{4}{*}{398.20} & \multirow{4}{*}{1.1030} & \multirow{4}{*}{4059.151} \\
\hline & Temperature & 0.2435 & 0.0656 & $0.0002 * * *$ & & & & \\
\hline & Humidity & 0.0444 & 0.0119 & $0.0002 * * *$ & & & & \\
\hline & Time & 1.0018 & 0.0615 & $0.0000 * * *$ & & & & \\
\hline \multirow{4}{*}{ Sarawak } & Constant & 13.9898 & 3.9439 & $0.0004 * * *$ & \multirow{4}{*}{361} & \multirow{4}{*}{416.41} & \multirow{4}{*}{1.1535} & \multirow{4}{*}{4393.553} \\
\hline & Temperature & -0.2043 & 0.0918 & $0.0261 * * *$ & & & & \\
\hline & Humidity & -0.0535 & 0.0207 & $0.0096^{* * *}$ & & & & \\
\hline & Time & 0.0623 & 0.0699 & $0.0373^{* * *}$ & & & & \\
\hline
\end{tabular}

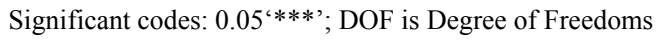




\section{Conclusions}

This study focused on the influence of climate factors on the occurrences of HFMD in five Malaysian states. Due to the existence of overdispersion issues in the data sets, this study used a GLM negative binomial model to examine the linear association between HFMD cases and climate factors. This study reveals several noteworthy findings regarding the link between climate factors and HFMD cases in five Malaysian states. The results, however, differ depending on the geographical location of the division region because different areas have varying climates. On the other hand, the study discovered that humidity and temperature are significant indicators of HFMD risk in Malaysia. These findings suggest that climate factors can be used as an early risk indicator that can benefit local health authorities in developing a simple climate-based disease early warning system in order to help minimize outbreaks. Future studies are suggested to further explore the impact of climate variables on HFMD in each state of Malaysia, taking into consideration additional factors such as geographical location, socio-demographics, and population density.

\section{Acknowledgements}

The authors would like to express their greatest appreciation to the Ministry of Health Malaysia for providing the HFMD data and the Malaysian Meteorological Department for providing the climate data. This work was supported by the Ministry of Higher Education under the Fundamental Research Grant Scheme FRGS/1/2020/STG06/UTM/02/3 and Research University Grant with vote no: QJ130000.3854.19J58 and Zamalah UTM Scholarship under Universiti Teknologi Malaysia.

\section{REFERENCES}

[1] T. H. Flewett, R. P. Warin, S. K. Clarke. Hand, foot, and mouth disease'associated with Coxsackie A5 virus, Journal of clinical pathology, Vol.16, No.1, 53-55, 1963.

[2] J. Alsop, T. H. Flewett,J. R. Foster. Hand-foot-and-mouth disease in Birmingham in 1959, British Medical Journal. Vol.2, No.5214, 1708-1711, 1960.

[3] Ministry of Health Malaysia, MOH. HAND, FOOT \& MOUTH DISEASE (HFMD). 2016. Available: http://www.myhealth.gov.my/en/hand-foot-mouth-diseasehfmd/.

[4] Centers for Disease Control and Prevention, CDC. Hand, Foot and Mouth Disease (HFMD). 2011. Available: https://www.cdc.gov/hand-foot-mouth/index.html.

[5] M. Y. Liu, W. Liu, J. Luo, Y. Liu, Y. Zhu, H. Berman, J. Wu. Characterization of an outbreak of hand, foot, and mouth disease in Nanchang, China in 2010, PloS one, Vol.6, No.9, 2011.

[6] M. Urashima, N. Shindo, N. Okabe, Seasonal models of herpangina and hand-foot-mouth disease to simulate annual fluctuations in urban warming in Tokyo, Japanese journal of infectious diseases, Vol. 56, No.2, 48-53, 2003.

[7] L. W. Ang, B. K. Koh, K. P. Chan, L. T. Chua, L. James, K. T. Goh, Epidemiology and control of hand, foot and mouth disease in Singapore, Ann Acad Med Singapore. Vol.38, No.2, 106-12, 2009.

[8] S. Chatproedprai, A. Theanboonlers, S. Korkong, C. Thongmee, S. Wananuku, Y. Poovorawan. Clinical and molecular characterization of hand-foot-and mouth disease in Thailand, 2008-2009, Jpn J Infect Dis, Vol. 63, No.4, 229-233, 2010.

[9] M. Ho, E. R. Chen, K. H. Hsu, S. J. Twu, K .T. Chen, S. F. Tsai, J. R. Wang, S. R. Shih. An epidemic of enterovirus 71 infection in Taiwan, New England Journal of Medicine, Vol.341, No.13, 929-935, 1999.

[10] WHO. Hand, foot and mouth disease a rising menace in Asia. 2009. Available: http://www.wpro.who.int/mediacen tre/news/2009/20090713/en/index.html

[11] K. Shekhar, M. S. Lye, O. Norlijah, F. Ong, L. M. Looi, R. Khuzaiah, I. Marzuki, I. Hussein, S. L. Wong, J. Mohan, M. Sinniah. Deaths in children during an outbreak of hand, foot and mouth disease in Peninsular Malaysia clinical and pathological characteristics, The Medical journal of Malaysia, Vol. 60, No.3, 297-304, 2005.

[12] Y. Podin, E. L. Gias, F. Ong, Y. W. Leong, S. F. Yee, M. A. Yusof, D. Perera, B. Teo, T. Y. Wee, S. C. Yao, S. K. Yao Sentinel surveillance for human enterovirus 71 in Sarawak, Malaysia: lessons from the first 7 years, BMC public health, Vol. 6, No. 1, 1-10, 2006.

[13] E. Ma, T. Lam, C. Wong, S. K. Chuang. Is hand, foot and mouth disease associated with meteorological parameters? Epidemiology \& Infection, Vol.138, No.12, 1779-1788, 2010.

[14] D. Onozuka, M. Hashizume. The influence of temperature and humidity on the incidence of hand, foot, and mouth disease in Japan, Science of the Total Environment, Vol. 410, 119-125, 2011.

[15] B. I. Kim, H. Ki, S. Park, E. Cho, B. C. Chun. Effect of climatic factors on hand, foot, and mouth disease in South Korea, 2010-2013, PloS one, Vol.11, No.6, 2016.

[16] Y. Liao, R. Ouyang, J. Wang, B. Xu. A study of spatiotemporal delay in hand, foot and mouth disease in response to weather variations based on SVD: a case study in Shandong Province, China, BMC Public health, Vol.15, No.1, 1-10, 2015.

[17] Y. L. Hii, J. Rocklöv, N. Ng. Short term effects of weather on hand, foot and mouth disease, PloS one, Vol.6, No.2, 2011.

[18] J. A. Nelder, R. W. Wedderburn. Generalized linear models, Journal of the Royal Statistical Society: Series A (General),Vol. 135, No.3, 370-384, 1972.

[19] N. M .Sham, I. Krishnarajah, M. Shitan, M. S. Lye. Time series model on hand, foot and mouth disease in Sarawak, 
Malaysia, Asian Pacific Journal of Tropical Disease, Vol.4, No.6, 469-472, 2014.

[20] N. M. N. NikNadia, I. C. Sam, S. Rampal, W. M. Z. WanNorAmalina, G. NurAtifah, K. Verasahib, C. C. Ong, M. MohdAdib, Y. F. Chan. Cyclical patterns of hand, foot and mouth disease caused by enterovirus A71 in Malaysia, PLoS neglected tropical diseases, Vol.10, No.3, 2016.

[21] M. H. Kutner, C. J. Nachtsheim, J. Neter, W. Li. Applied linear statistical models, (Vol. 5), New York: McGraw-Hill Irwin, 2005

[22] J. D. Curto, J. C. Pinto. The corrected vif (cvif), Journal of Applied Statistics, Vol.38, No.7, 1499-1507, 2011.

[23] D. W. Marquaridt. Generalized inverses, ridge regression, biased linear estimation, and nonlinear estimation, Technometrics, Vo.12, No.3, 591-612, 1970.

[24] J. P. Hoffmann. Generalized linear models: An applied approach, Pearson College Division, 2004.

[25] A. Pedan. Analysis of count data using the SAS system, Proceedings of the 26th Annual SAS Users Group International Conference, Vol.26, 226-247, 2001.

[26] A. C. Cameron, P. K.Trivedi. Regression-based tests for overdispersion in the Poisson model, Journal of econometrics, Vol.46, No.3, 347-364, 1990.

[27] N. E. Breslow. Extra- Poisson variation in log- linear models, Journal of the Royal Statistical Society: Series C (Applied Statistics), Vol. 33, No.1, 38-44, 1983.

[28] H. Akaike. Information theory and an extension of the maximum likelihood principle, In Selected papers of hirotugu akaike Springer, New York, NY, 199-213, 1998.

[29] T. C. Thanh. EFFECTS OF CLIMATE VARIATIONS ON HAND-FOOT-MOUTH DISEASE IN HO CHI MINH CITY, Vietnam Journal of Science and Technology, Vol.54, No.2A, 120. 2016.

[30] S. Chen, X. Liu, Y. Wu, G. Xu, X. Zhang, S. Mei, Z. Zhang, M. O'Meara, M. C. O'Gara, X. Tan, L. Li. The application of meteorological data and search index data in improving the prediction of HFMD: A study of two cities in Guangdong Province, China, Science of The Total Environment, Vol.652, 1013-1021, 2019.

[31] H. Qi, Y. Chen, D. Xu, H. Su, L. Zhan, Z. Xu, Y. Huang, Q. $\mathrm{He}, \mathrm{Y}$. Hu, H. Lynn, Z. Zhang. Impact of meteorological factors on the incidence of childhood hand, foot, and mouth disease (HFMD) analyzed by DLNMs-based time series approach, Infectious diseases of poverty, Vol.7, No.1, 1-10, 2018.

[32] D. C. Huang, J. F. Wang. Monitoring hand, foot and mouth disease by combining search engine query data and meteorological factors, Science of the Total Environment, Vol.612, 1293-1299, 2018.

[33] F. Gou, X. Liu, J. He, D. Liu, Y. Cheng, H. Liu, X. Yang, K. Wei, Y. Zheng, X. Jiang, L. Meng. Different responses of weather factors on hand, foot and mouth disease in three different climate areas of Gansu, China, BMC infectious diseases, Vol.18, No.1, 1-10, 2018.

[34] C. Guo, J. Yang, Y. Guo, Q. Q. Ou, S. Q. Shen, C. Q. Ou, Q.Y. Liu. Short-term effects of meteorological factors on pediatric hand, foot, and mouth disease in Guangdong, China: a multi-city time-series analysis, BMC infectious diseases, Vol.16, No.1, 1-9, 2016. 